\title{
Risk factors and early outcomes of acute renal injury after thoracic aortic endograft repair for type B aortic dissection
}

This article was published in the following Dove Press journal:

Therapeutics and Clinical Risk Management

17 August 2017

Number of times this article has been viewed

\author{
Songyuan Luo* \\ Huanyu Ding* \\ Jianfang Luo \\ Wei Li \\ Bing Ning \\ Yuan Liu \\ Wenhui Huang \\ Ling Xue \\ Ruixin Fan \\ Jiyan Chen
}

Cardiology Department, Guangdong Cardiovascular Institute, Guangdong

Provincial Key Laboratory of

Coronary Heart Disease Prevention,

Guangdong General Hospital,

Guangdong Academy of Medical

Sciences, Guangzhou, Guangdong,

China

*These authors contributed equally to this work
Background: Thoracic endovascular aortic repair (TEVAR) has become an emerging treatment modality for acute type B aortic dissection (TBAD) patients in recent years. The risk factors and impacts of acute kidney injury (AKI) after percutaneous TEVAR, however, have not been widely established.

Methods: We retrospectively studied the clinical records of 305 consecutive patients who admitted to our institution and had TEVAR for TBAD between December 2009 and June 2013. The patients were routinely monitored for their renal functions preoperatively until 7 days after TEVAR. The Kidney Disease Improving Global Guidelines (KDIGO) criteria were used for AKI.

Results: Of the total 305 consecutive patients, 84 (27.5\%) developed AKI after TEVAR, comprising $66(21.6 \%)$ patients in KDIGO stage 1, 6 (2.0\%) patients in stage 2 and $12(3.9 \%)$ patients in stage 3. From the logistic regression analysis, systolic blood pressure (SBP) on admission $>140 \mathrm{mmHg}$ (odds ratio [OR], 2.288; 95\% CI, 1.319-3.969) and supra-aortic branches graft bypass hybrid surgery (OR, 3.228; 95\% CI, 1.526-6.831) were independent risk factors for AKI after TEVAR. Local anesthesia tended to be a protective factor (OR, 0.563; 95\% CI, 0.316-1.001). The preoperative renal function, angiotensin-converting enzyme inhibitor/ angiotensin receptor blocker or statin administration, volume of contrast agent, range of TBAD and false lumen involving renal artery were not associated with post-operation AKI. The inhospital mortality and major adverse events were markedly increased with the occurrence of AKI (7.1\% vs $0.9 \%, P=0.006 ; 14.3 \%$ vs $3.2 \%, P<0.001$, respectively).

Conclusions: TEVAR for TBAD has a high incidence of AKI, which is associated with worse in-hospital outcomes. SBP on admission and supra-aortic branches graft bypass hybrid surgery were the most significant risk factors. Renopreventive measures should be considered in high-risk patients.

Keywords: risk factor, acute renal injury, endovascular repair, aortic dissection

\section{Introduction}

Despite its infrequent progression to permanent dialysis dependence, acute kidney injury (AKI) is associated with extended intensive care, prolonged hospital stay, diminished quality of life and shorter long-term survival. ${ }^{1-4}$ AKI after thoracic endovascular aortic repair (TEVAR) of thoracic aortic diseases has been documented in several studies, with incidences ranging from $1.5 \%$ to $34 \%{ }^{5-7}$

TEVAR is emerging as an important treatment option for type B aortic dissection (TBAD) to induce aortic remodeling by sealing the proximal entry tear, to prevent late complications and to avoid the risk associated with open surgery at the same time. ${ }^{8-12}$ Several less invasive novel techniques have been introduced in aortic dissection 
endovascular repair in recent years, such as percutaneous technique, hybrid approach and rapid artificial cardiac pacing for inducing hypotension during stent deployment. However, the impact of these techniques on the renal dysfunction after TEVAR is still an area of ongoing research. ${ }^{13-15}$

As far as we know, little research has been focused on the risk factors and impacts of AKI after TEVAR on TBAD. Most studies have focused on the types of conditions requiring TEVAR, including aneurysms, dissections and transections to penetrating ulcers. ${ }^{3,7}$ However, TBAD presents with other pathologic states that may influence renal function in a number of ways: 1) the blood supply for the side branch of aorta from the true lumen (TL)/false lumen (FL) may influence renal perfusion. Side branch artery occlusions caused by obstruction from the dissection flap, which can either prolapse across a vessel origin without entering it (dynamic obstruction) or directly extend into a vessel (static obstruction); ${ }^{16}$ 2) the TL/FL hemodynamic change and inflammatory response after aortic stent graft deployment may impact on the renal function postoperatively; ${ }^{17}$ 3) because of a complicated TL and FL association, the contrast agent may be administrated more to make sure whether the stent graft is implanted in the TL and at the right place and 4) the blood pressure (BP) change during procedure such as controlling depressurization during stent deployment may reduce the renal perfusion. All of these features may lead to postoperative renal dysfunction, such as contrast-induced nephropathy, renal ischemia, renal artery embolization or occlusion, renal infarction or ischemia-reperfusion injury. ${ }^{18}$ The purpose of this paper is to determine the risk factors and impact of AKI on TEVAR for TBAD.

\section{Methods}

\section{Patient population}

Data from all patients admitted to the Guangdong Cardiovascular Institute, Guangdong General Hospital, who underwent percutaneous TEVAR for TBAD between December 2009 and June 2013 were retrospectively analyzed. Patients who received TEVAR, including complicated or uncomplicated TBAD, with definite detecting tear entry were included into the study. Data were collected by cardiologists and were entered by EpiData software 3.1 (The EpiData Association, Odense, Denmark) using consistency check on 2 copies. The study was approved by the ethics committees of Guangdong General Hospital, and written informed consent was obtained from all the patients participated in the study.

Exclusion criteria included 1) previous endovascular repair for aortic disease, 2) medical history of dialysisdependent renal failure, 3) patients who have received extra renal artery revascularization, 4) associated on-pump or off-pump bypass graft surgery, 5) patients who are deemed technically unsuccessful, 6) connective tissue disorders and $7)$ age $<18$ years or pregnant. Patients were also excluded in case of death in the operating room before or during procedure ( $n=3)$, lack of test of renal function postoperatively $(n=12)$ or lack of computed tomography (CT) image in the institution's medical record system $(\mathrm{n}=6)$. About 305 patients met the criteria and were recruited into the study.

\section{Perioperative management}

Patients presenting with a nonemergent status and a preoperative creatinine $>2.0 \mathrm{mg} / \mathrm{dL}$ underwent preoperative hydration. We gave the patients isotonic saline $(1 \mathrm{~mL} / \mathrm{kg} /$ hour $)$ from 12 hours preprocedure to 24 hours postprocedure. We routinely administered prophylactic antibiotics (cefuroxime) 30 minutes to 1 hour before procedure and then again 12 hours after the procedure.

\section{Description of procedure}

Percutaneous TEVAR was conducted following standard procedures described previously, ${ }^{13}$ which began with 18-gauge needle puncture of the common femoral arteries (CFAs) under fluoroscopy. According to CT image, the entry points were based on the anatomy relationship between CFA and femoral head. Two or multiple 6F Perclose ProGlide devices were deployed in the CFA before upsizing to a $20-25 \mathrm{~F}$ sheath. The sutures were secured to close the arteriotomy at the end of the procedure. The construction of the pathway in the TL for stent graft delivery was guided and confirmed by sectional angiography or intravascular ultrasound. The thoracic stent grafts used included Medtronic Talent (Medtronic, Minneapolis, MN, USA), Zenith TX2 (COOK, Bjaeverskov, Denmark) and Hercules (Microport, Shanghai, China), which were approved by the State Food and Drug Administration during the period of the study. Briefly controlled hypotension was utilized during device deployment, and then again if balloon aortoplasty was performed by using the rapid artificial cardiac pacing technique. ${ }^{15,19}$ Since November 2009, stent size selection for all cases has been oversized by $10 \%-15 \%$. To prevent posterior circulation ischemia, we performed supra-aortic branch graft bypass surgery before TEVAR in cases of right vertebral artery dominance with insufficient aortic arch landing zone. ${ }^{20}$ The patients underwent regional anesthesia unless needed additional supra-aortic branches graft bypass surgery.

\section{Definitions}

Aortic dissection was defined as disruption of the medial layer provoked by intramural bleeding, resulting in separation of the aortic wall layers and subsequent formation of a TL and an 
FL with or without communication. The AKI was diagnosed according to the KDIGO criteria from Kidney Disease Improving Global Guidelines. ${ }^{21}$ We used the maximum change in serum creatinine level in the first 7 days after surgery to classify patients according to the KDIGO criteria. The estimated glomerular filtration rate (eGFR) was calculated with the chronic kidney disease epidemiology collaboration formular. ${ }^{22}$ The major adverse events were defined as death, stroke, paraplegia and the need for renal replacement therapy (RRT).

\section{Statistical analysis}

Mean \pm SD or medians (interquartile range) were used to describe continuous variables; intergroup differences were evaluated by Student's $t$-test or nonparametric MannWhitney $U$-test, depending on the distribution of variables. Categorical variables were presented as frequencies, and percentages were compared by Fisher's exact test or $\chi^{2}$ test. Stepwise multivariate logistic regression variables were fitted from variables found to have marginal associations with AKI on univariate testing $(P<0.10)$. Odds ratios (ORs), 95\% CIs and probability values are reported. All statistical analyses were performed using SPSS software, version 19.0 (IBM Inc., Chicago, IL, USA).

\section{Results \\ Population}

A total of 305 consecutive patients were recruited: 84 (27.5\%) developed AKI after TEVAR, consisting of 66 (21.6\%) patients with KDIGO stage 1, 6 (2.0\%) patients in stage 2 and $12(3.9 \%)$ patients in stage 3 . The mean age was $54.5 \pm 10.3$ years, and 269 (88.2\%) of patients were men. About 252 (82.6\%) patients had a history of hypertension. Forty-four (14.4\%) patients were on angiotensin-converting enzyme inhibitor/angiotensin receptor blocker, with no significant difference between the 2 groups. The systolic blood pressure (SBP) and diastolic blood pressure (DBP) tended to be higher in the AKI group than in the non-AKI group (SBP: $148.63 \pm 24.57 \mathrm{mmHg}$ vs $138.45 \pm 22.31$ $\mathrm{mmHg}, P=0.001$; DBP: $83.21 \pm 13.43 \mathrm{mmHg}$ vs $79.34 \pm 13.13$ $\mathrm{mmHg}, P=0.013)$. There was no significant difference between the 2 groups in terms of pre-operation renal function (creatinine: $130.60 \pm 141.04 \mu \mathrm{mol} / \mathrm{L}$ vs $116.08 \pm 80.18 \mu \mathrm{mol} / \mathrm{L}$, $P=0.620$; blood urea nitrogen $(\mathrm{BUN}): 7.00 \pm 4.40 \mathrm{mmol} / \mathrm{L}$ vs $6.61 \pm 3.91 \mathrm{mmol} / \mathrm{L}, P=0.593$ and eGFR: $72.27 \pm 28.48$ $\mathrm{mL} / \mathrm{min} / 1.73 \mathrm{~m}^{2}$ vs $72.02 \pm 24.6 \mathrm{~mL} / \mathrm{min} / 1.73 \mathrm{~m}^{2}, P=0.743$, respectively). The results of the white blood cell count, hemoglobin (HGB), alanine aminotransferase (ALT), aspartate aminotransferase (AST), albumin (ALB), uric acid (URIC), and D-dimer (DDI) were similar in both groups, as shown in Table 1.

\section{Aortic dissection features}

About 144 (47.1\%) patients were presented with pleural effusion, which was comparable between the AKI group and the non-AKI group ( $47.5 \%$ vs $46.4 \%, P=0.699$ ). There was no significant difference between the AKI group and the non-AKI group in terms of FL involvement of celiac trunk, superior mesenteric artery, inferior mesenteric artery and renal artery. The characteristics of the vascular situation of aortic dissection are presented in Table 2.

\section{Operative data and outcome}

Thirty-eight (12.4\%) patients received supra-aortic branch bypass with a higher incidence in the AKI group compared with the non-AKI group ( $23.8 \%$ vs $8.1 \%, P=0.004)$. There was no significant difference in the volume of contrast medium and the number of cover stent observed between the AKI group and the non-AKI group. The in-hospital mortality, RRT and major adverse events were markedly increased with the occurrence of AKI (death: $7.1 \%$ vs $0.9 \%, P=0.006$; RRT: $6.0 \%$ vs $0.5 \%, P=0.007$, major adverse events: $14.3 \%$ vs $3.2 \%, P<0.001$, respectively; Table 3$)$. The in-hospital mortality $(P<0.001)$ and major adverse events $(P<0.001)$ were associated with the severity of AKI (Figure 1).

\section{Risk factors for AKI}

Owing to the limited positive events, we performed the logistic regression analysis with the following variables: age $>60$ years, male gender, SBP when admitted to hospital (>140 mmHg), local anesthesia, supra-aortic branches graft bypass hybrid surgery, diabetes mellitus, coronary artery disease and at least one side of renal artery involvement by FL. SBP > 140 mmHg (OR, 2.288; 95\% CI, 1.319-3.969) on admission and supra-aortic branches graft bypass hybrid surgery (OR, 3.228; 95\% CI, 1.526-6.831) were independent risk factors for AKI after TEVAR. Local anesthesia tended to be a protective factor (OR, 0.563; 95\% CI, 0.316-1.001). The FL involving renal artery was not an independent risk factor (Table 4).

\section{Discussion}

The current study indicates that AKI is a common problem after percutaneous TEVAR, which is associated with inhospital mortality and complications. In our study, we found that the incidence of AKI after TEVAR was $27.5 \%$, including $21.6 \%$ in KDIGO stage $1,2.0 \%$ in stage 2 and $3.9 \%$ in stage 3 . The in-hospital outcomes of death and events were associated with the severity of AKI. Patients in stages 2 and 3 had significant higher rates of in-hospital mortality and major adverse events. Similar incidence of AKI was found in the 
Table I Baseline clinical characteristics of patient population

\begin{tabular}{|c|c|c|c|}
\hline & $\begin{array}{l}\text { AKI group } \\
(n=84)\end{array}$ & $\begin{array}{l}\text { Non-AKI group } \\
(n=22 I)\end{array}$ & $P$-value \\
\hline Age (years) & $55.32 \pm 10.14$ & $54.22 \pm 10.35$ & 0.317 \\
\hline Male & $75(89.3)$ & $194(87.8)$ & 0.716 \\
\hline Hypertension & $75(89.3)$ & $177(80.1)$ & 0.058 \\
\hline Diabetes mellitus & $9(10.7)$ & $15(6.8)$ & 0.255 \\
\hline Coronary artery disease & $10(11.9)$ & I7 (7.7) & 0.247 \\
\hline Smoke & $38(45.2)$ & $105(47.5)$ & 0.722 \\
\hline Heart rate & $80.56 \pm 12.89$ & $77.87 \pm 12.05$ & 0.173 \\
\hline Systolic blood pressure on admission $(\mathrm{mmHg})$ & $148.63 \pm 24.57$ & $|38.45 \pm 22.3|$ & 0.001 \\
\hline Diastolic blood pressure on admission $(\mathrm{mmHg})$ & $83.21 \pm 13.43$ & $79.34 \pm 13.13$ & 0.013 \\
\hline ACEI/ARB & $12(14.3)$ & $32(14.5)$ & 0.966 \\
\hline $\mathrm{CCB}$ & $12(14.3)$ & $32(14.5)$ & 0.966 \\
\hline Statin & $27(32.1)$ & $68(30.8)$ & 0.817 \\
\hline HGB $(g / L)$ & $|26.4| \pm \mid 8.14$ & $128.07 \pm 18.2$ & 0.787 \\
\hline WBC $\left(10^{\circ} / \mathrm{L}\right)$ & $10.92 \pm 4.64$ & $11.11 \pm 3.94$ & 0.343 \\
\hline $\operatorname{PLT}\left(10^{9} / \mathrm{L}\right)$ & $232.72 \pm 106.57$ & $238.06 \pm 105.18$ & 0.636 \\
\hline $\mathrm{HbAIC}(\%)$ & $5.42 \pm 1.83$ & $5.7 I \pm 2.13$ & 0.867 \\
\hline TR $(\mathrm{mmol} / \mathrm{L})$ & $1.54 \pm 0.82$ & $1.48 \pm 1.01$ & 0.311 \\
\hline $\mathrm{TC}(\mathrm{mmol} / \mathrm{L})$ & $4.45 \pm 0.96$ & $4.29 \pm 0.98$ & 0.189 \\
\hline $\mathrm{HDL}-\mathrm{C}(\mathrm{mmol} / \mathrm{L})$ & $1.03 \pm 0.28$ & $1.08 \pm 0.76$ & 0.770 \\
\hline LDL-C (mmol/L) & $2.57 \pm 0.72$ & $2.5 \pm 0.82$ & 0.417 \\
\hline ALB $(g / L)$ & $31.35 \pm 7.6$ & $32.47 \pm 5.52$ & 0.260 \\
\hline \multirow[t]{2}{*}{ D-dimer (ng/mL) } & $\mathrm{I}, 264.16 \pm \mathrm{I}, 809.35$ & $\mathrm{I}, 726.67 \pm 2,|\mathrm{I}| \mathrm{I} .56$ & 0.106 \\
\hline & $\mathrm{I}, 213.16 \pm \mathrm{I}, 789.48$ & & \\
\hline Serum creatinine $(\mu \mathrm{mol} / \mathrm{L})$ & $|30.60 \pm| 4 \mid .04$ & $116.08 \pm 80.18$ & 0.620 \\
\hline BUN (mmol/L) & $7 \pm 4.4$ & $6.61 \pm 3.91$ & 0.593 \\
\hline eGFR $\left(\mathrm{mL} / \mathrm{min} / \mathrm{l} .73 \mathrm{~m}^{2}\right)$ & $72.27 \pm 28.48$ & $72.02 \pm 24.6$ & 0.743 \\
\hline
\end{tabular}

Notes: Data presented as $\mathrm{n}(\%)$; mean \pm standard deviation.

Abbreviations: $A C E I$, angiotensin-converting enzyme inhibitor; ALB, albumin; AKI, acute kidney injury; ARB, angiotensin receptor blocker; BUN, blood urea nitrogen; CCB, calcium channel blocker; eGFR, estimated glomerular filtration rate; HGB, hemoglobin; HbAIC, hemoglobin A Ic; HDL-C, high-density lipoprotein-cholesterol; LDL-C, low-density lipoprotein-cholesterol; PLT, platelet; TR, triglyceride; TC, total cholesterol; WBC, white blood cell.

study by Zhu et al, ${ }^{23}$ which identified AKI in $48(30.8 \%)$ of 156 TEVAR for TBAD patients according to RIFLE (risk, injury, failure, lose and end-stage renal disease) classification, with 7 (14.5\%) patients requiring continuous RRT. Other previous studies, however, have suggested the rates of

Table 2 Aortic dissection features and AKI

\begin{tabular}{|c|c|c|c|}
\hline & $\begin{array}{l}\text { AKI group } \\
(n=84)\end{array}$ & $\begin{array}{l}\text { Non-AKI group } \\
(n=221)\end{array}$ & $P$-value \\
\hline \multicolumn{4}{|c|}{ Blood supply of left renal artery $n$ (\%) } \\
\hline True lumen & $58(69.0)$ & $167(75.6)$ & 0.218 \\
\hline False lumen & $20(23.8)$ & $34(15.4)$ & \\
\hline True lumen and false lumen & $6(7.1)$ & $20(9.0)$ & \\
\hline \multicolumn{4}{|c|}{ Blood supply of right renal artery $n$ (\%) } \\
\hline True lumen & $62(73.8)$ & $164(74.2)$ & 0.945 \\
\hline False lumen & $15(17.9)$ & $4 \mid(\mid 8.6)$ & \\
\hline True lumen and false lumen & $7(8.3)$ & $16(7.2)$ & \\
\hline \multicolumn{4}{|c|}{ Number of renal arteries involved $\mathrm{n}(\%)$} \\
\hline 0 & $39(46.4)$ & $117(52.9)$ & 0.596 \\
\hline I & $42(50.0)$ & $97(43.9)$ & \\
\hline 2 & $3(3.6)$ & $7(3.2)$ & \\
\hline Pleural effusion $\mathbf{n}(\%)$ & $39(46.4)$ & $105(47.5)$ & 0.898 \\
\hline
\end{tabular}

Abbreviation: $\mathrm{AKI}$, acute kidney injury.
AKI after endovascular repair varying from $1.5 \%$ to $34 \% .^{5-7}$ The observed differences in incidence rates could be due to a couple of reasons. First, the lack of consistent definition of renal failure used in these studies could account for the differences in the published rates of AKI after endovascular repair. In this study, we chose the criteria of KDIGO AKI which referenced the AKIN criteria from Acute Kidney Injury Network to define the renal dysfunction as it is a more sensitive indicator of renal function and can be used as a risk factor to predict long-term survival. ${ }^{24,25}$ Second, the differences in various study populations may be another reason. The previous studies focusing on AKI after endovascular repair included patients of abdominal aortic aneurysm, thoracic aortic aneurysms, Stanford TBADs, penetrating thoracic ulcers and traumatic aortic transection. ${ }^{5-7}$ The rates of postprocedure AKI after endovascular repair for thoracic or abdominal aortic aneurysm alone were relatively low ranging from $2 \%$ to $17 \%,{ }^{26-29}$ when compared with TEVAR for TBAD which ranged from $27.5 \%$ to $30.8 \% .^{23}$ The differences in pathophysiology between aortic dissection and aneurysm may also be factor to consider, including hemodynamic 
Table 3 Operative data and outcome

\begin{tabular}{|c|c|c|c|}
\hline & $\begin{array}{l}\text { AKI group } \\
(n=84)\end{array}$ & $\begin{array}{l}\text { Non-AKI group } \\
(n=22 I)\end{array}$ & $\overline{P \text {-value }}$ \\
\hline Rapid artificial pacing & $66(78.6)$ & $168(76.0)$ & 0.637 \\
\hline Percutaneous & $47(56.0)$ & $133(60.2)$ & 0.502 \\
\hline Local anesthesia & $27(32.1)$ & $115(52.0)$ & 0.002 \\
\hline Supra-aortic branches graft bypass hybrid surgery & $20(23.8)$ & $18(8.1)$ & $<0.001$ \\
\hline Volume of contrast agent $(\mathrm{mL})$ & $168.2 \pm 46.2$ & $153.5 \pm 35.2$ & 0.104 \\
\hline Multi-stent implantation & $7(8.3)$ & $23(10.4)$ & 0.587 \\
\hline \multicolumn{4}{|l|}{ Stent number } \\
\hline I & $77(91.7)$ & $198(89.6)$ & 0.589 \\
\hline 2 & $6(7.1)$ & $22(10.0)$ & \\
\hline 3 & $\mathrm{I}(\mathrm{I} .2)$ & $\mathrm{I}(0.5)$ & \\
\hline \multicolumn{4}{|l|}{ Outcomes } \\
\hline RRT & $5(6.0)$ & $\mathrm{I}(0.5)$ & 0.007 \\
\hline Stroke & $3(3.6)$ & $3(1.4)$ & 0.352 \\
\hline Paraplegia & $\mathrm{I}(\mathrm{I} .2)$ & $\mathrm{I}(0.5)$ & 0.476 \\
\hline Death & $6(7.1)$ & $2(0.9)$ & 0.006 \\
\hline Major adverse events & $12(14.3)$ & $7(3.2)$ & $<0.001$ \\
\hline Endoleak & $13(15.5)$ & $21(9.5)$ & 0.139 \\
\hline Fever & $30(35.7)$ & $73(33.0)$ & 0.658 \\
\hline Duration of procedure (min) & $92.6 \pm 23.5$ & $94.1 \pm 21.7$ & 0.599 \\
\hline Time of inducted hypotension (s) & $6.7 \pm 3.1$ & $6.2 \pm 2.6$ & 0.157 \\
\hline
\end{tabular}

Notes: Data presented as $\mathrm{n}(\%)$; mean \pm standard deviation.

Abbreviations: AKI, acute kidney injury; RRT, renal replacement therapy.

changes by the TL/FL, the dissection flap, the load of contrast agent and the controlled BP depressurization during stent deployment.

For the risk factors of AKI, SBP on admission $>140 \mathrm{mmHg}$ and supra-aortic branch graft bypass hybrid surgery were identified as independent risk factors by multivariate regression analysis. Local anesthesia tended to be a protective factor (OR, 0.563; 95\% CI, 0.316-1.001). Previous studies have found risk factors of AKI after endovascular aortic repair to include chronic kidney disease, acute dissection, complicated dissection, mal-perfusion complications, ${ }^{18}$ thoracoabdominal extention, postoperative transfusion, ${ }^{7}$ intraoperative hypotension, stroke, sepsis, lengthy procedures and number of stents. ${ }^{30}$ Again, the different findings may be because of the different aortic pathological changes, operative strategies and perioperative administration.

Higher BP was associated with the occurrence of AKI. In a previous study, ${ }^{31}$ multivariate analysis showed that SBP on admission and bilateral renal artery involvement were strong predictors of preoperative AKI for TBAD. Higher SBP on admission may be associated with renal artery involvement because the renin-angiotensin-aldosterone system, which is activated because of renal artery involvement, induces a dramatic increase in BP. Furthermore, higher SBP may lead to sustainable expansion of the FL, causing generalized ischemia to the kidney leading to AKI. It was found that BP variability is an independent risk factor for the prognosis of aortic dissection. We could not identify BP variability in this
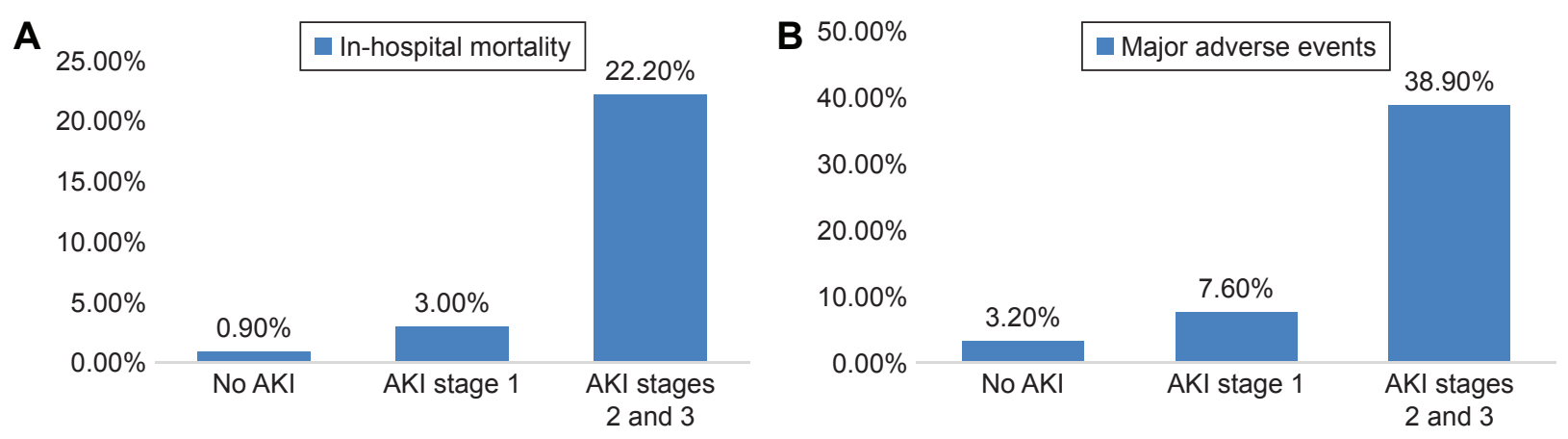

Figure I In-hospital mortality (A) and major adverse events (B) with AKI stages. Note: Major adverse events: death, stroke, paraplegia and the need for RRT. Abbreviations: $\mathrm{AKI}$, acute kidney injury; RRT, renal replacement therapy. 
Table 4 Risk factors of AKI

\begin{tabular}{|c|c|c|c|}
\hline & OR & $95 \% \mathrm{Cl}$ & $P$-value \\
\hline Age $>60$ years & 1.651 & $(0.900-903.027)$ & 0.105 \\
\hline Male & 0.709 & $(0.288-1.742)$ & 0.453 \\
\hline $\begin{array}{l}\text { Systolic blood pressure on } \\
\text { admission }>140 \mathrm{mmHg}\end{array}$ & 2.288 & $(1.319-3.969)$ & 0.003 \\
\hline Local anesthesia & 0.563 & $(0.316-1.00 I)$ & 0.050 \\
\hline $\begin{array}{l}\text { Supra-aortic branches graft } \\
\text { bypass hybrid surgery }\end{array}$ & 3.228 & $(1.526-6.83 I)$ & 0.002 \\
\hline Diabetes mellitus & 2.138 & $(0.8 I 6-5.60 I)$ & 0.122 \\
\hline Coronary artery disease & 1.186 & $(0.467-3.012)$ & 0.719 \\
\hline $\begin{array}{l}\text { At least one renal artery } \\
\text { involve by dissection }\end{array}$ & 1.070 & $(0.617-1.857)$ & 0.809 \\
\hline
\end{tabular}

Abbreviations: $\mathrm{AKI}$, acute kidney injury; OR, odds ratio.

current study from the retrospective design. However, our data indicate that higher BP on admission is not only a risk factor for AKI preoperatively but also post-TEVAR.

Supra-aortic branches graft bypass hybrid surgery often require general anesthesia, lengthy procedures, more blood loss, postoperative transfusion, higher rates of intraoperative hypotension, more severe inflammatory response and assisted mechanical ventilation. These factors may take the responsibility for a higher incidence of AKI after TEVAR. ${ }^{23,30,32,33}$

The most important features of this current study are taking the changes of aortic dissection anatomy into account. Effusion and partial thrombosis were reported to be associated with unfavorable prognosis. ${ }^{34,35}$ However, it seems they may not be related to AKI in this current study. The FL directly extending to the renal artery may be associated with AKI after TEVAR. However, the TL/FL relationship between renal artery may not be an independent risk factor. Owing to the limited sample size of this study, we could not provide enough evidence to confirm or refute this issue. Further studies are needed to explore the real implication of renal artery involvement by the FL. It may be easier to predict that the end-organ malperfusion caused by TBAD will turn better after TEVAR with improvement in the blood supply by the TL after TEVAR. However, the perfusion of side branch artery after TEVAR may be a little more complicated as the end-organ ischemia may deteriorate when blood is supplied by TL and FL at the same time or just FL. Therefore, the renal malperfusion will not always be relieved after TEVAR. Similar findings documented in previous reports corroborate the fact that patients, who had AKI before TEVAR was performed, had no improvements in their renal function but rather had higher incidences of renal failure after TEVAR. ${ }^{31}$ In conclusion, it is vitally important that we pay more attention to the hemodynamic changes of side branch artery involvement by an FL.

Several limitations exist in this study. It was a retrospective, uncontrolled study and therefore subject to inherent limitations in the study design. The study is also limited by the lack of urine output measurements. Moreover, as we did not monitor the blood flow of renal artery, we could not define the exact time of renal hypoperfusion. The short- and longterm mortality was also unclear in AKI patients with TBAD; thus, in-hospital mortality may have been underestimated.

\section{Conclusion}

In summary, our data indicate that AKI is still a common problem after percutaneous TEVAR for TBAD, which is associated with worse in-hospital outcomes. Specifically, SBP on admission $>140 \mathrm{mmHg}$ and supra-aortic branches graft bypass hybrid surgery were the most relevant predictive factors of AKI after TEVAR. However, the extents of dissection and branch artery involvements, the renal function preoperatively, AECI/ARB or statin administration, volume of contrast agent and range of TBAD were not related to AKI. Renal preventive measures should be considered in high-risk patients. The significance of imaging and anatomic changes in AKI after TEVAR are worth further studies.

\section{Acknowledgments}

The authors thank Nianjin Xie and Jie Li for their great help in contribution to conception, design and acquisition of data. They also thank Lambert Tetteh Appiah (Komfo Anokye Teaching Hospital, Kumasi, Ghana) for the revision of text.

The study was supported by the Science and Technology Programme of Guangdong Province (2014A020215023), Science and Technology Programme of Guangzhou (201508020114) and Science and Technology Programme of Guangzhou (201300000180).

\section{Disclosure}

The authors report no conflicts of interest in this work.

\section{References}

1. Park B, Mavanur A, Drezner AD, Gallagher J, Menzoian JO. Clinical impact of chronic renal insufficiency on endovascular aneurysm repair. Vasc Endovascular Surg. 2006;40(6):437-445.

2. Boyle JR. Acute kidney injury predicts mortality after endovascular aortic repair. Eur J Vasc Endovasc Surg. 2015;50(4):431.

3. Pisimisis GT, Bechara CF, Barshes NR, Lin PH, Lai WS, Kougias P. Risk factors and impact of proximal fixation on acute and chronic renal dysfunction after endovascular aortic aneurysm repair using glomerular filtration rate criteria. Ann Vasc Surg. 2013;27(1):16-22.

4. Lok CE, Austin PC, Wang H, Tu JV. Impact of renal insufficiency on short- and long-term outcomes after cardiac surgery. Am Heart J. 2004; 148(3):430-438.

5. Eggebrecht H, Breuckmann F, Martini S, et al. Frequency and outcomes of acute renal failure following thoracic aortic stent-graft placement. Am J Cardiol. 2006;98(4):458-463.

6. Fairman RM, Criado F, Farber M, et al; VALOR Investigators. Pivotal results of the medtronic vascular talent thoracic stent graft system: the VALOR trial. J Vasc Surg. 2008;48(3):546-554. 
7. Piffaretti G, Mariscalco G, Bonardelli S, et al. Predictors and outcomes of acute kidney injury after thoracic aortic endograft repair. J Vasc Surg. 2012;56(6):1527-1534.

8. Song TK, Donayre CE, Walot I, et al. Endograft exclusion of acute and chronic descending thoracic aortic dissections. J Vasc Surg. 2006;43(2): 247-258.

9. Nienaber CA, Rousseau H, Eggebrecht H, et al. Randomized comparison of strategies for type B aortic dissection: the INvestigation of STEnt Grafts in Aortic Dissection (INSTEAD) trial. Circulation. 2009 120(25):2519-2528

10. Nienaber CA, Kische S, Rousseau H, et al; INSTEAD-XL trial. Endovascular repair of type $\mathrm{B}$ aortic dissection: long-term results of the randomized investigation of stent grafts in aortic dissection trial. Circ Cardiovasc Interv. 2013;6(4):407-416.

11. Fattori R, Montgomery D, Lovato L, et al. Survival after endovascular therapy in patients with type B aortic dissection: a report from the International Registry of Acute Aortic Dissection (IRAD). JACC Cardiovasc Interv. 2013;6(8):876-882.

12. Erbel R, Aboyans V, Boileau C, et al; ESC Committee for Practice Guidelines. 2014 ESC Guidelines on the diagnosis and treatment of aortic diseases: document covering acute and chronic aortic diseases of the thoracic and abdominal aorta of the adult. The task force for the diagnosis and treatment of aortic diseases of the European Society of Cardiology (ESC). Eur Heart J. 2014;35(41):2873-2926.

13. Ni ZH, Luo JF, Huang WH, et al. Totally percutaneous thoracic endovascular aortic repair with the preclosing technique: a case-control study. Chin Med J (Engl). 2011;124(6):851-855.

14. Zhang T, Jiang W, Lu H, Liu J. Thoracic endovascular aortic repair combined with assistant techniques and devices for the treatment of acute complicated Stanford type B aortic dissections involving aortic arch. Ann Vasc Surg. 2016;32:88-97.

15. Chen J, Huang W, Luo S, Yang D, Xu Z, Luo J. Application of rapid artificial cardiac pacing in thoracic endovascular aortic repair in aged patients. Clin Interv Aging. 2014;9:73-78.

16. Hiratzka LF, Bakris GL, Beckman JA, et al. 2010 ACCF/AHA/AATS/ ACR/ASA/SCA/SCAI/SIR/STS/SVM Guidelines for the diagnosis and management of patients with thoracic aortic disease. A Report of the American College of Cardiology Foundation/American Heart Association Task Force on Practice Guidelines, American Association for Thoracic Surgery, American College of Radiology, American Stroke Association, Society of Cardiovascular Anesthesiologists, Society for Cardiovascular Angiography and Interventions, Society of Interventional Radiology, Society of Thoracic Surgeons, and Society for Vascular Medicine. J Am Coll Cardiol. 2010;55(14):e27-e129.

17. Chang CK, Chuter TA, Niemann CU, et al. Systemic inflammation, coagulopathy, and acute renal insufficiency following endovascular thoracoabdominal aortic aneurysm repair. J Vasc Surg. 2009;49(5):1140-1146.

18. Twine CP, Boyle JR. Renal dysfunction after EVAR: time for a standard definition. J Endovasc Ther. 2013;20(3):331-333.

19. Huang WH, He PC, Luo JF, et al. [A randomized controlled trial of rapid artificial cardiac pacing in thoracic endovascular aortic repair.] Zhonghua Yi Xue Za Zhi. 2011;91(24):1668-1672. Chinese.

20. Fu WG, Dong ZH, Wang YQ, et al. Strategies for managing the insufficiency of the proximal landing zone during endovascular thoracic aortic repair. Chin Med J (Engl). 2005;118(13):1066-1071.
21. Kellum JA, Lameire N. Diagnosis, evaluation, and management of acute kidney injury: a KDIGO summary (Part 1). Crit Care. 2013; 17(1):204.

22. Matsushita K, Mahmoodi BK, Woodward M, et al. Comparison of risk prediction using the CKD-EPI equation and the MDRD study equation for estimated glomerular filtration rate. JAMA. 2012;307(18): 1941-1951.

23. Zhu J, Chen S, Jin G, et al. Acute renal injury after thoracic endovascular aortic repair of Stanford type B aortic dissection: incidence, risk factors, and prognosis. J Formos Med Assoc. 2014;113(9): 612-619.

24. Khwaja A. KDIGO clinical practice guidelines for acute kidney injury. Nephron Clin Pract. 2012;120(4):c179-c184.

25. James M, Bouchard J, Ho J, et al. Canadian Society of Nephrology commentary on the 2012 KDIGO clinical practice guideline for acute kidney injury. Am J Kidney Dis. 2013;61(5):673-685.

26. Saratzis A, Melas N, Mahmood A, Sarafidis P. Incidence of Acute Kidney Injury (AKI) after Endovascular Abdominal Aortic Aneurysm Repair (EVAR) and impact on outcome. Eur J Vasc Endovasc Surg. 2015;49(5): 534-540.

27. Ruan ZB, Zhu L, Yin YG, Chen GC. Risk factors of early and late mortality after thoracic endovascular aortic repair for complicated stanford B acute aortic dissection. J Card Surg. 2014;29(4): 501-506.

28. Drews JD, Patel HJ, Williams DM, Dasika NL, Deeb GM. The impact of acute renal failure on early and late outcomes after thoracic aortic endovascular repair. Ann Thorac Surg. 2014;97(6):2027-2033; discussion 2033.

29. Kim M, Brady JE, Li G. Anesthetic technique and acute kidney injury in endovascular abdominal aortic aneurysm repair. J Cardiothorac Vasc Anesth. 2014;28(3):572-578.

30. Pisimisis GT, Khoynezhad A, Bashir K, Kruse MJ, Donayre CE, White RA. Incidence and risk factors of renal dysfunction after thoracic endovascular aortic repair. J Thorac Cardiovasc Surg. 2010;140 (Suppl 6):S161-S167.

31. Ren HM, Wang X, Hu CY, et al. Relationship between acute kidney injury before thoracic endovascular aneurysm repair and in-hospital outcomes in patients with type B acute aortic dissection. J Geriatr Cardiol. 2015;12(3):232-238.

32. Wald R, Waikar SS, Liangos O, Pereira BJ, Chertow GM, Jaber BL. Acute renal failure after endovascular vs open repair of abdominal aortic aneurysm. J Vasc Surg. 2006;43(3):460-466; discussion 466.

33. Ambler GK, Coughlin PA, Hayes PD, Varty K, Gohel MS, Boyle JR. Incidence and outcomes of severe renal impairment following ruptured abdominal aortic aneurysm repair. Eur J Vasc Endovasc Surg. 2015; 50(4):443-449.

34. Tsai TT, Evangelista A, Nienaber CA, et al; International Registry of Acute Aortic Dissection. Partial thrombosis of the false lumen in patients with acute type B aortic dissection. NEngl J Med. 2007;357(4): 349-359.

35. Mukherjee D, Evangelista A, Nienaber CA, et al. Implications of periaortic hematoma in patients with acute aortic dissection (from the International Registry of Acute Aortic Dissection). Am J Cardiol. 2005;96(12): 1734-1738.
Therapeutics and Clinical Risk Management

\section{Publish your work in this journal}

Therapeutics and Clinical Risk Management is an international, peerreviewed journal of clinical therapeutics and risk management, focusing on concise rapid reporting of clinical studies in all therapeutic areas outcomes, safety, and programs for the effective, safe, and sustained use of medicines. This journal is indexed on PubMed Central, CAS,

\section{Dovepress}

EMBase, Scopus and the Elsevier Bibliographic databases. The manuscript management system is completely online and includes a very quick and fair peer-review system, which is all easy to use. Visit http://www.dovepress.com/testimonials.php to read real quotes from published authors. 